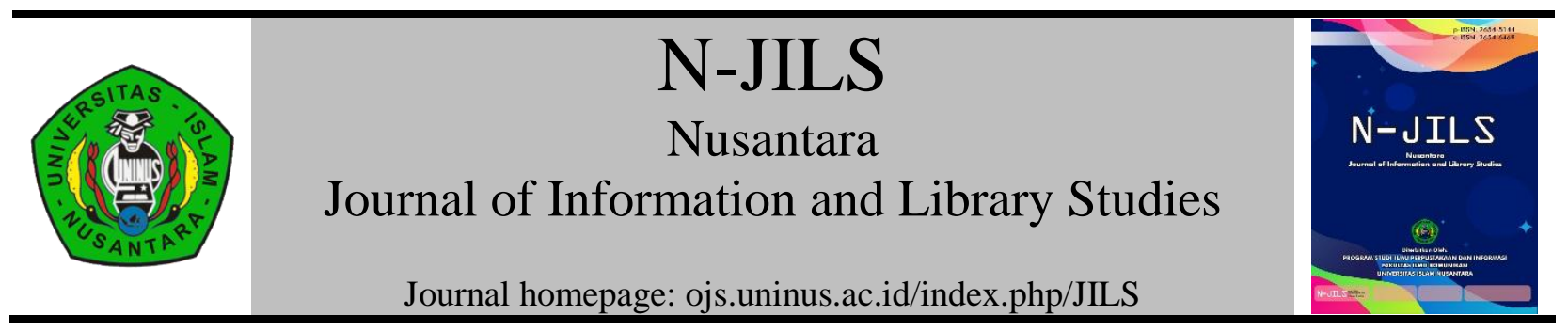

\title{
Kegiatan Alih Media Koleksi Antiquariat Di Pusat Perpustakaan Dan Penyebaran Teknologi Pertanian
}

\section{Antiquariat Collection Media Transfer Activities At The Library And Distribution Center For Agricultural Technology}

\author{
Siti Kartika Safanawati ${ }^{1}$, Samson CMS $^{2}$ \\ ${ }^{1}$ Universitas Padjadjaran \\ ${ }^{2}$ Universitas Padjadjaran \\ e-mail: ${ }^{1}$ siti16038@mail.unpad.ac.id, ${ }^{2}$ samson.cms@ unpad.ac.id
}

\begin{tabular}{ll}
\hline ARTICLE INFO & ABSTRACT \\
\hline Article history & The Center for Library and Distribution of \\
Received [May, 2020] & Agricultural Technology is one of the special libraries \\
Revised [June, 2020] & that manages rare library materials, namely \\
Accepted [June, 2020] & antiquariat library materials. Antiquariat library \\
Available Online [June, 2020] & material is a rare library from the Dutch colonial era \\
which contains information about agriculture. & Antiquariat library materials require special handling \\
to preserve existing information, this conservation \\
process is called the Preservation process. \\
Preservation is a way to preserve library materials \\
which is not only physical preservation but also \\
includes preservation of information contained \\
therein. Preservation is an effort so that the \\
information contained therein can still be accessed and \\
prevented from extinction. This study uses a \\
qualitative approach, with more emphasis on the way \\
of description in expressing the phenomena \\
experienced by research subjects. As for the subjects of
\end{tabular}




\begin{tabular}{|c|c|}
\hline & $\begin{array}{l}\text { the study are the Library and Agricultural } \\
\text { Technology Dissemination of Bogor City. The object } \\
\text { under study is the preservation process carried out by } \\
\text { the Central Library and Distribution of Agricultural } \\
\text { Technology in preserving antiquariat library } \\
\text { materials. The results of this study indicate that the } \\
\text { preservation process carried out by the Central } \\
\text { Library and Distribution of Agricultural Technology } \\
\text { has been going well. The process of observation carried } \\
\text { out by the Central Library and Distribution of } \\
\text { Agricultural Technology is to carry out the process of } \\
\text { media transfer by digitizing using two methods, } \\
\text { namely scanning and capturing. The results of the } \\
\text { digitization are presented in the form of e-books and } \\
\text { CD-Roon that can be accessed by users only at the } \\
\text { Agricultural Library and Technology Center. }\end{array}$ \\
\hline & $\begin{array}{l}\text { Keyword:preservation; digitalization; antiquariat; } \\
\text { PUSTAKA }\end{array}$ \\
\hline $\begin{array}{l}\text { Kata kunci:preservasi; } \\
\text { digitalisasi; antiquariat; } \\
\text { PUSTAKA }\end{array}$ & $\begin{array}{l}\text { ABSTRAK } \\
\text { Pusat Perpustakaan dan Penyebaran Teknologi } \\
\text { Pertanian merupakan salah satu perpustakaan khusus } \\
\text { pertanian yang mengelolaan bahan pustaka langka, } \\
\text { yaitu bahan pustaka antiquariat. Bahan pustaka } \\
\text { antiquariat merupakan bahan pustaka langka } \\
\text { peninggalan masa penjajahan Belanda yang berisikan } \\
\text { informasi-informasi seputar pertanian bahan pustaka } \\
\text { antiquariat ini memerlukan penanganan khusus guna } \\
\text { melestarikan informasi yang ada, proses pelestarian } \\
\text { ini disebut proses preservasi. Preservasi merupakan } \\
\text { cara pelestarian bahan pustaka yang bukan hanya } \\
\text { pelestarian fisiknya namun termasuk juga pelestarian } \\
\text { terhadap informasi yang terdapat didalamnya. } \\
\text { Preservasi merupakan upaya agar informasi yang ada } \\
\text { didalamnya masih bisa diakses dan mencegah dari } \\
\text { kepunahan. Penelitian ini menggunakan pendekatan } \\
\text { kualitatif, dengan lebih menekankan cara deskripsi } \\
\text { dalam mengungkapkan fenomena yang dialami oleh } \\
\text { subyek penelitian. Adapun yang menjadi subyek } \\
\text { penelitian yaitu Pusat Perpustakaan dan Penyebaran } \\
\text { Teknologi Pertanian Kota Bogor. Objek yang dikaji } \\
\text { adalah proses preservasi yang dilakukan oleh Pusat } \\
\text { Perpustakaan dan Penyebaran Teknologi Pertanian } \\
\text { dalam melestarikan bahan pustaka antiquariat. Hasil } \\
\text { dari penelitian ini menunjukan bahwa proses } \\
\text { preservasi yang dilakukan oleh Pusat Perpustakaan } \\
\text { dan Penyebaran Teknologi Pertanian ini sudah } \\
\text { berjalan secara baik. Proses presevasi yang dilakukan } \\
\text { oleh Pusat Perpustakaan dan Penyebaran Teknologi }\end{array}$ \\
\hline
\end{tabular}


Pertanian adalah melakukan proses alih media dengan cara digitalisasi dengan menggunakan dua cara yaitu scanning dan capturing. Hasil dari digitalisasi tersebut disajikan dalam bentuk e-book dan $C D$-Roon yang bisa diakses pemustaka hanya di Pusat Perpustakaan dan Teknologi Pertanian.

(C) 2020 NJILS. All rights reserved.

\section{A. PENDahuluan}

Dunia perpustakaan semakin hari semakin berkembang seiring dengan perkembangan ilmu pengetahuan dan teknologi informasi. Hal ini menyebabkan berbagai jenis perpustakaan terus melakukan inovasi dalam mendukung dan memenuhi kebutuhan ilmu pengtahuan serta informasi yang diperlukan oleh masyarakat. Teknologi Informasi saat ini telah menyebar hampir disemua bidang tidak terkecuali di perpustakaan. Perpustakaan sebagai institusi pengelolaan informasi merupakan salah satu bidang penerapan teknologi informasi yang berkembang pesat. Penerapan teknologi informasi sebagai sarana untuk menyimpan, mendapatkan dan menyebarluaskan informasi ilmu pengetahuan dalam format koleksi media elektronik yang mampu menciptakan wadah yang lebih luas laguu bagi hubungan ketiga hal tersebut. Salah satu hal yang saat ini sangat diperhatikan oleh perpustakaan adalah pengembangan koleksi media elektronik.

Dalam penelitian kali ini penulis mengangkat penerapan teknologi informasi sebagai salah satu saranan untuk menyimpan, mendapatkan dan menyebarluaskan informasi dengan bentuk alih media koleksi antiquariat yang dilakukan oleh Pusat Perpustakaan dan Penyebaran Teknologi Pertanian Kota Bogor. Proses alih media koleksi yang dilakukan di Pusat Perpustakaan dan Penyebaran Teknologi Pertanian ini dilakukan sebagai upaya pelestarian dan konservasi bahan pustaka khusus yang dimiliki oleh Pusat Perpustakaan dan Penyebaran Teknologi Pertanian yaitu koleksi Antiquariat.

Pelestarian Koleksi sendiri merupakan hal penting yang dilakukan oleh Perpustakaan apabila terdapat bahan koleksi yang memiliki nilai informasi yang tinggi dan dapat berguna bagi peradaban dan pengembangan ilmu pengetahuan. Oleh karena itu, penulis menilai bahwa pelestarian dan konservasi merupakan hal yang penting sebagai upaya melestarian informasi yang tersimpan didalam bahan pustaka. Salah satu upaya pelestarian yaitu dengan digitalisasi. Menurut Silvana (2018) digitalisasi adalah proses alih media dari bentuk tercetak, audio, 
maupun video menjadi bentuk digital. Digitalisasi dilakukan untuk membuat arsip dokemen bentuk digital, untuk fungsi fotokopi dan untuk membuat koleksi perpustakaan digital.

Dari latar belakang di atas maka penulis memiliki beberapa tujuan, sebagai berikut: untuk mengetahui bagaimana pelestarian bahan pustaka yang terdapat di Pusat Perpustakaan dan Penyebaran Teknologi Pertanian. Serta untuk mengetahui bagaimana proses alih media koleksi Antiquariat yang dilakukan di Pusat Perpustakaan dan Penyebaran Teknologi Pertanian.

\section{B. TINJAUAN PUSTAKA}

\section{PRESERVASI}

Preservasi merupakan salah satu upaya yang dilakukan oleh Perpustakaan untuk melestarikan dan menjaga bahan pustaka atau koleksi yang dimiliki, baik berupa buku, CD-ROM atau koleksi digital lainnya. Preservasi mencakup pengcegahan kerusakan pada bahan pustaka, penanggulangan kerusakan seperti kertas pada buku yang mulai lapuk, sobek atau kerusakan lainnya, serta proses alih media suatu bahan koleksi yang dinilai memiliki nilai informasi yang perlu dilindungi. Hal ini selaras dengan pernyataan beberapa ahli mengenai preservasi. SulistyoBasuki (2010) mengatakan bahwa preservasi mencakup semua aspek usaha dalam melestarikan bahan pustaka dan arsip, termasuk didalamnya kebijakan pengelolaan, keuangan, sumber daya manusia, metode, dan teknik penyimpanan. Restorasi menurut Lasa Hs, (2009) disebut juga dengan reparasi yakni tindakan yang dilakukan untuk memperbaiki bahan pustaka atau dokumen lain yang sudah rusak atau lapuk.

Definisi lain yang dikemukan oleh Ballofet tentang preservasi adalah sebagai berikut.

"Preservation includes safeguarding not only physical materials but also information. To this end, reformatting, replacement, and the use of protective containers are employed to extend access to information that might be lost once paper or electronic books or documents deteriorate"

(Preservasi merupakan cara pelestarian bahan pustaka yang bukan hanya pelestarian fisiknya namun termasuk juga pelestarian terhadap informasi yang terdapat didalamnya. Preservasi merupakan upaya agar informasi yang ada didalamnya dapat diakses walaupun fisik aslinya sudah rusak.) (Ballofet. Nelly \& Jenny Hille, 2005)

Pandangan lain mengenai preservasi yang dikemukan oleh John Feather adalah sebagai berikut.

"Preservation is an aspect of the management of the library. Its objective is to ensure that information survives in an accessible and usable form for as long as it is wanted." 
(Preservasi merupakan aspek dari manajemen perpustakaan yang secara objektif memastikan bahwa informasi dapat lestari, dapat diakses dan dapat digunakan selama informasi itu dibutuhkan.) (Feather, 1996)

\section{MEDIA ELEKTRONIK}

Media elektronik adalah bahan koleksi pustaka yang berupa non cetak, biasanya medianya menggunakan elektronik atau energi elektromekanis bagi pengguna akhir untuk mengakses kontennya. Menurut Glossary yang dikeluarkan oleh African Koleksi media elektronik library, yang dimasuksud dengan koleksi media elektronik adalah:

"This is an electronic Internet based collection of information that is normallu found in hard copy, but converted to a computer compatible format." (Singkatnya koleksi media elektronik dapat dipahami sebagai koleksi infomasi dalam bentuk eletronik atau koleksi media elektronik yang mungkin terdapat juga dalam kondisi cetak, yang dapat secara luas diakses menggunakan media computer dan sejenisnya.)

\section{DIGITALISASI}

Menurut Silvana (2018) menjelaskan bahwa digitalisasi adalah proses alih media dari bentuk tercetak, audio, maupun video menjadi bentuk digital. Digitalisasi dilakukan untuk membuat arsip dokemen bentuk digital, untuk fungsi fotokopi dan untuk membuat koleksi perpustakaan digital. Sedangkan, Pendit menjelaskan bahwa proses digitalisasi adalah proses mengubah dokumen tercetak menjadi dokumen digital. Proses digitalisasi untuk naskah kuno ataupun buku langka yang sangat tua dapat dilakukan dengan kamera yang memiliki resolusi tinggi agar mampu memotret setiap detai dari naskah tersebut. Tetapi, untuk koleksi naskah yang sudah sangat rapuh dibutuhkan laminating dengan plastik khusus sebelum difoto atau di-scan (Pendit, 2007).

Proses digitalisasi secara singkat adalah melakukan kegiatan seleksi, pemisahan halaman sqatu per satu, melakukan kegiatan foto atau scan pada koleksi, melakukan pemindahan file kedalam bentuk CD dan kedalam bentuk lain sesuai kebijakan perpustakaan. Seiring dengan pendapat Lasa Hs yang menjelasakan bahwa digitalisasi merupakan proses pengelolaan dokumen tercetak/ printed document menjadi dokumen elektronik (Lasa, 2005). 


\section{ANTIQUARIAT}

Buku antiquariat adalah buku yang mempunyai pengertian hampir sama dengan buku langka, yaitu buku yang telah berumur setidaknya 50 tahun, menjadi langka dikarenakan buku tersebut sudah tidak diterbitkan lagi dan tidak terdapat di pasaran. Buku antiquariat yang terdapat di Pusat Perpustakaan dan Penyebaran Teknologi Pertanian tak jarang mempunyai bentuk fisik yang unik seperti contohnya ukuran buku yang besar dan cover yang terbuat dari kulit binatang. Hal tersebut yang membuat keunikannya menjadi antik, dan mayoritas buku antiquariat di Pusat Perpustakaan dan Penyebaran Teknologi Pertanian bersubjek pertanian dan juga terdapat bahan pustaka yang disebut Indonesiana.Beberapa bahan pustaka antiquariat bahkan hanya terdapat di Pusat Perpustakaan dan Penyebaran Teknologi Pertanian.

Ecyclopedie of library and information science mendefiniskan buku langka merupakan sebuah koleksi khusus yang tidak hanya berarti langka, namun buku-buku tersebut oleh perpustakaan memiliki atribut khusus, dapat berdiri sendiri atau saling berhubungan dengan lainnya. Ciri-ciri koleksi langka disebutkan Margana (2013) di antaranya dokumen telah berusia tua, jumlah sangat terbatas dan tidak ada dipasaran, tidak ditulis atau diterbitkan kembali, dan memiliki keunikan bahasa maupun isi. Koleksi langka banyak berisi informasi warisan budaya (cultural heritage). Definisi warisan budaya menurut Shimray and Ramaiah ( 2017) adalah sebagai ekspresi, adat istiadat, ritual, artefak, nilai-nilai yang dikembangkan beberapa generasi, yang berwujud (tangible) maupun tidak berwujud (intangible), yang diwarisi dari generasi sebelumnya, dan menghubungkan masa lampau dan masa kini, sehingga merupakan kunci bagi masyarakat dalam menemukan jati dirinya.

\section{METODE PENELITIAN}

Metode yang digunakan dalam penelitian adalah metode kualitatif. Metode kualitatif adalah "penelitian yang menghasilkan prosedur analisis yang tidak menggunakan prosedur analisis statistic atau cara kuantifikasi lainnya". Penelitian kualitatif didasarkan pada upaya membangun pandangan mereka yang diteliti dengan rinci, dibentuk dengan kata-kata, gambaran holistic dan rumit (Meleong, 2010). Menurut pengertian tersebut penelitian akan lebih dapat mengungkapkan pemecahan masalah menggunakan metode kualitatif dengan menekankan cara deskriptif dalam mengungkapkan kejadian yang dialami oleh subjek penelitian. Pada penelitian ini yang menjadi fokus adalah proses preservasi dengan cara alih media yang dilakukan oleh 
Pusat Perpustakaan dan Penyebaran Teknologi Pertanian dalam upaya pelestarian bahan pustaka langka, yaitu bahan pustaka antiquariat.

Proses pengambilan data yang dilakukan oleh peneliti adalah dengan cara observasi. Observasi menurut Sutrisno Hadi ( 2007) mengemukakan bahwa, observasi merupakan suatu proses yang kompleks, suatu proses yang tersusun dari pelbagai proses biologis dan psikologis. Observasi yang dilakukan dalam penelitian ini adalah observasi berperan serta (participant observation), peneliti melakukan pengamatan serta ikut melakukan dan merasakan oleh subyek penelitian. Observasi yang dilakukan peneliti adalah dengan secara langsung melakukan proses preservasi yang dilakukan serta melakukan dokumentasi.

Subyek Penelitian adalah Pusat Perpustakaan dan Penyebaran Teknologi Pertanian yang beralamatkan di Jl. Ir. Djuanda No. 20, Paledang, Bogor - Jawa Barat. Adapun website Pusat Perpustakaan dan Penyebaran Teknologi Pertanian adalah www.pustaka.setjen.pertanian.go.id. Sedangkan emailnya adalah pustaka@pertanian.go.id. Waktu pelaksanaan penelitian pada 8 Juli hingga 16 Agustus 2019.

\section{HASIL DAN PEMBAHASAN}

Preservasi yang dilakukan oleh Pusat Perpustakaan dan Penyebaran Teknologi Pertanian merupakan upaya pelestarian informasi pada bahan pustaka tua dan langka, salah satunya yaitu bahan pustaka antiquariat. Preservasi yang dilakukan adalah alih media bahan pustaka cara digitalisasi. Proses digitalisasi ini dilakukan terhadap bahan pustaka antiquariat proses memiliki dua cara, Scanning dan Capturing yaitu menggunakan Scanner dan ATIZ. Pusat Perpustakaan dan Penyebaran Teknologi Pertanian sendiri memiliki target capaian yaitu dalam satu tahun melakukan digitalisasi sebanyak 30.000 lembar.

Proses digitalisasi memiliki beberapa tahapan yaitu sebagai berikut: Langkah awal dari proses alih media ini Document Selecting, yaitu menentukan koleksi yang layak untuk dialih mediakan. Koleksi yang dinilai layak untuk dilakukan proses alih media harus melalui proses sebagai berikut. Langkah kedua adalah melakukan scanning atau capturing. Proses scanning 
digunakan untuk bahan pustaka yang kualitas kertasnya tidak rapuh dan ukuran buku tidak terlalu besar. Sedangkan proses capturing menggunakan alat khusus bernama ATIZ yang didalamnya terdapat perangkat lunak khusus untuk mendigitalisasikan, yaitu Bookdrive Capture

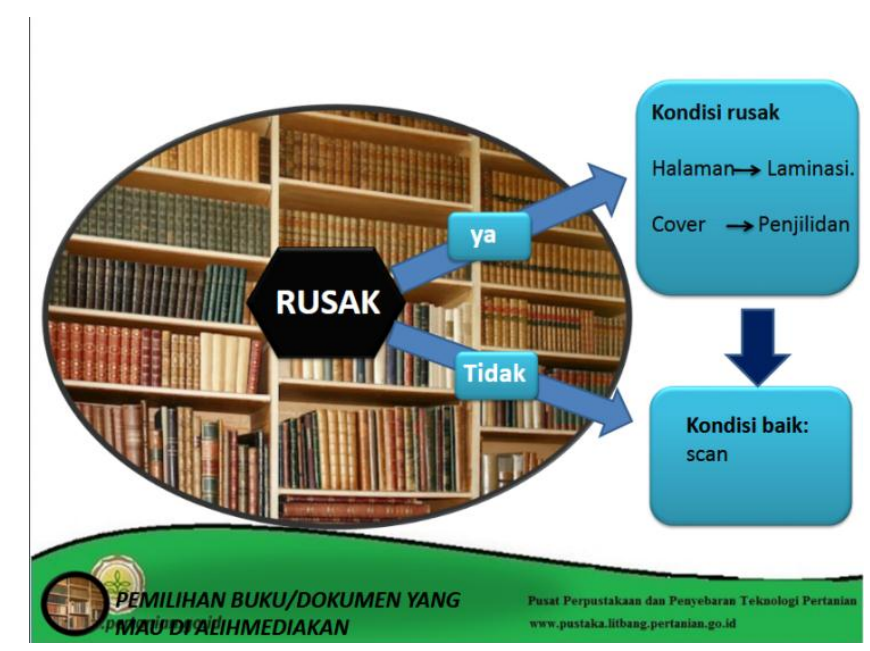

Gambar 1 Pemilihan Buku/Document Selecting

Sumber: Power Point Pusat Perpustakaan dan Penyebaran Teknologi Pertanian

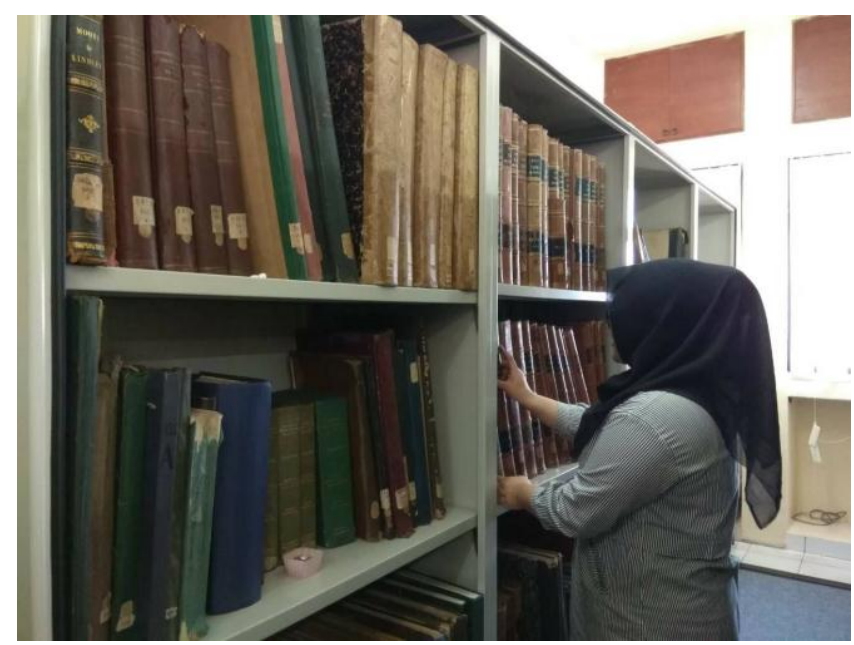

Gambar 2 Proses Document Selecting

Sumber: Dokumentasi Pribadi

Proses digitalisasi dilakukan dengan cara scanning menggunakan scanner dilakukan untuk bahan pustaka yang sudah melewati seleksi dokumen yang layak dan sesuai dengan kriteria. Setelah dokumen dinilai layak untuk proses digitalisasi, bahan pustaka tersebut akan 
melalui proses scan sesuai dengan urutan buku dan menghasilkan dokumen dalam bentuk $p d f$. Setelah berbentuk $p d f$, bahan pustaka tersebut disimpan dalam pangkalan data perpustaka.

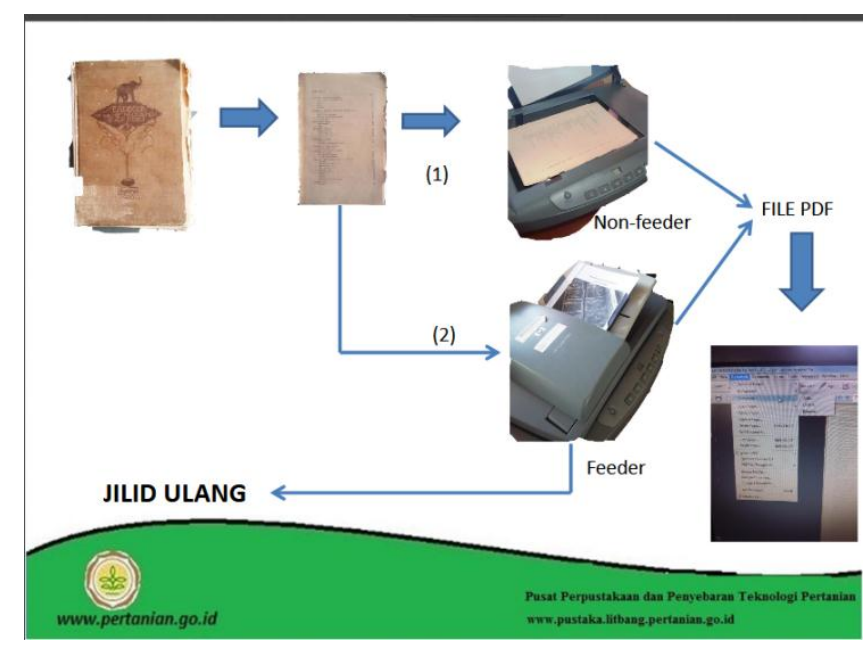

Gambar 3. Proses Scanning

Sumber: Power Point Pusat Perpustakaan dan Penyebaran Teknologi Pertanian

Digitalisasi dengan cara capturing atau dengan alat ATIZ, pada proses ini ada beberapa pengaturan yang dilakukan oleh Pusat Perpustakaan dan Penyebaran Teknologi Pertanian mengacu pada standar yang didapat dari Perpustakaan Nasioanal Republik Indonesia. Standarnya pengaturannya adalah sebagai berikut; pertama, proses capturing dengan menggunakan kamera digital yang sudah terkoneksi dengan alat ATIZ dengan pengaturan kamera disesuaikan dengan kebutuhan dalam proses pengambilan gambar seperti pengaturan ISO, Aperture, dan Shutter speed untuk menghasilkan kualitas gambar yang baik. Kedua, setalah pengambilan gambar proses selanjutnya adalah proses cropping, hasil foto buku dilakukan croping untuk mendapatkan bagian penting dari buku tersebut. Ketiga, setelah selesai melakukan cropping seluruh bagian buku, selanjutnya data tersebut disimpan dalam bentuk untuk dilakukan editing pemberian watermark dan pengecekan penyusunan halaman dari hasil buku yang telah dicapture. Keempat, proses pemberian Watermark yaitu berupa logo dari Kementerian Pertanian, guna mencegah pengambilan bahan secara illegal. Proses ini mengunakan aplikasi Adobe PDF. 


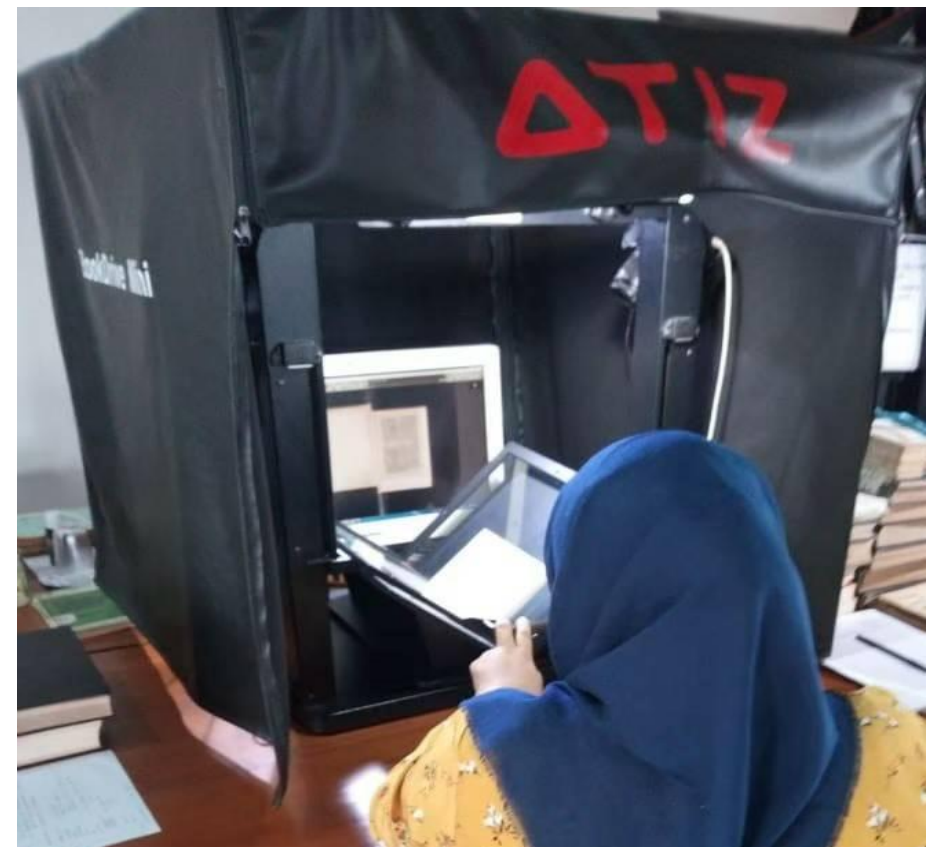

Gambar 4 Proses Capturing menggunakan ATIZ Sumber: Dokumentasi Pribadi

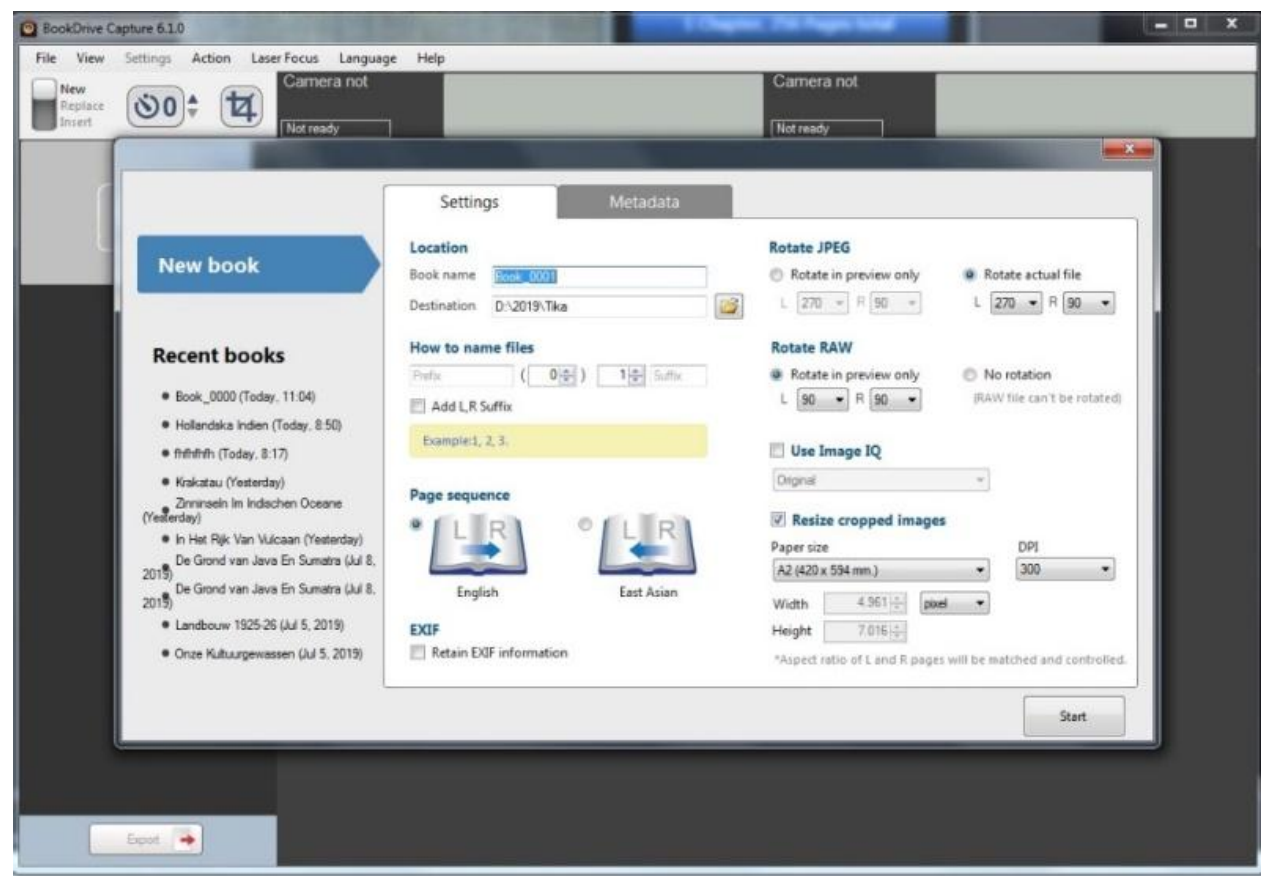

Gambar 5 Bookdrive Setting

Sumber: Dokumentasi Pribadi 


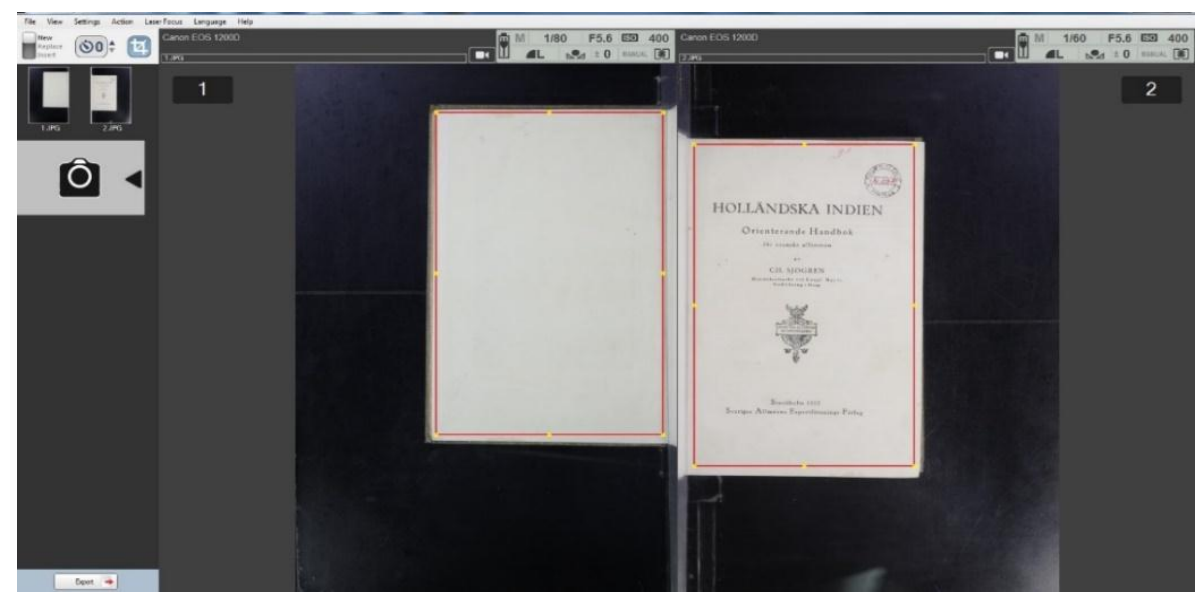

Gambar 6 Bookdrive Capturing

Sumber: Dokumentasi Pribadi

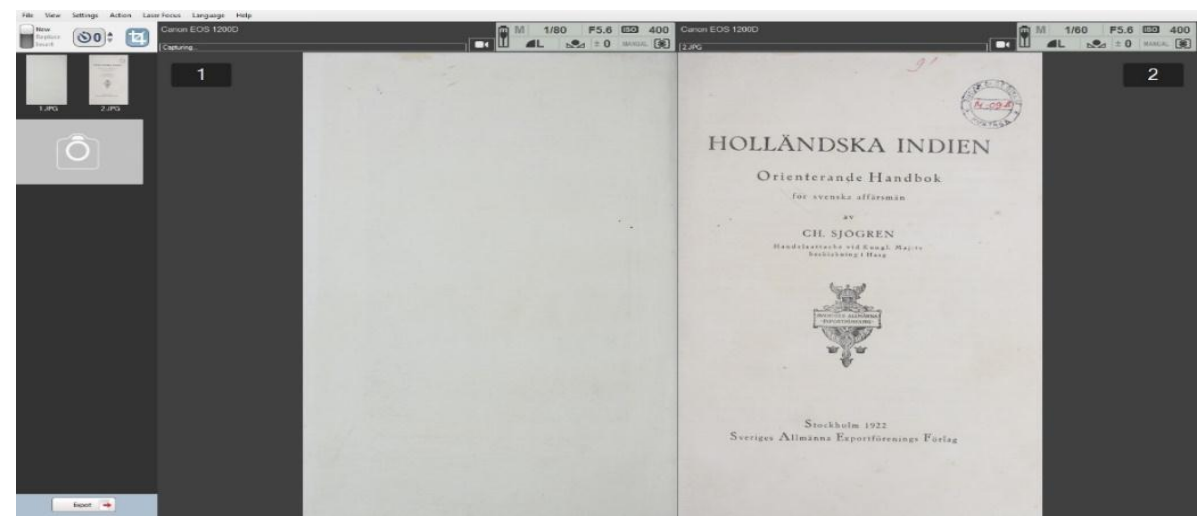

Gambar 7 Hasil Cropping

Sumber: Dokumentasi Pribadi

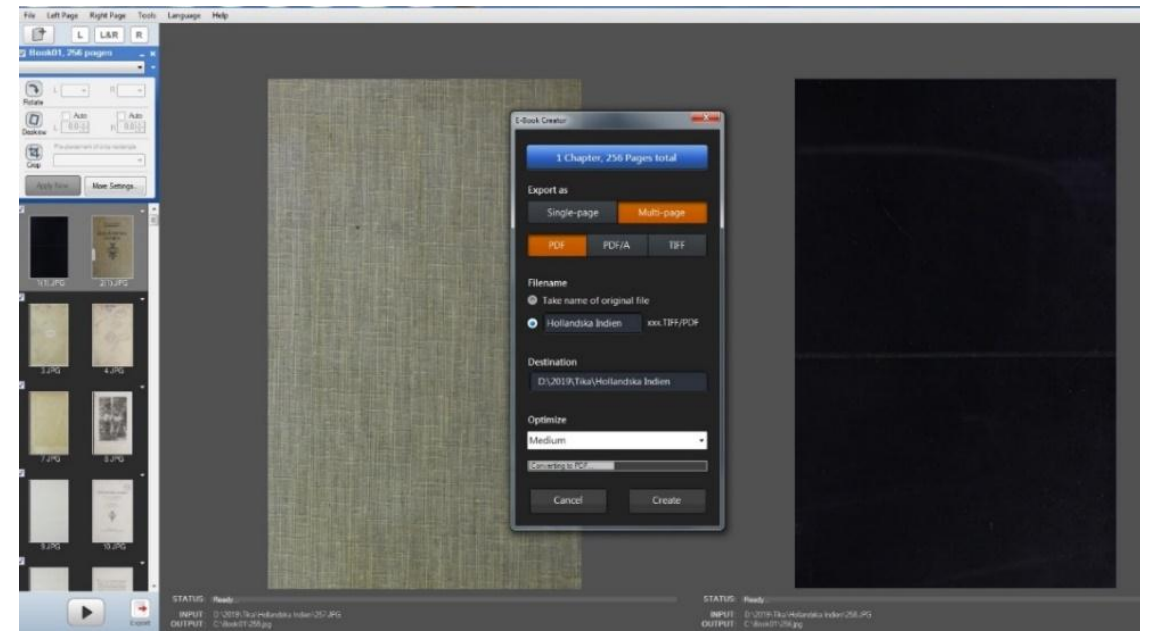

Gambar 8 Bookdrive Penyimpanan

Sumber: Dokumentasi Pribadi 
Hasil dari scanning dan capturing berbentuk PDF selanjutnya diubah kedalam bentuk buku elektronik (e-book) yang tersedia dalam bentuk flipping book. Proses Flipping Book ini mengunakan aplikasi Flippingbook Publisher.Proses ini digunakan agar e-book dapat secara mudah dibaca dalam bentuk digital dan terasa seperti sedang membaca buku fisik. Buku elektronik ini selanjutnya disimpan dalam hard disk externalI milik perpustakaan dan pada $C D$ Rom.

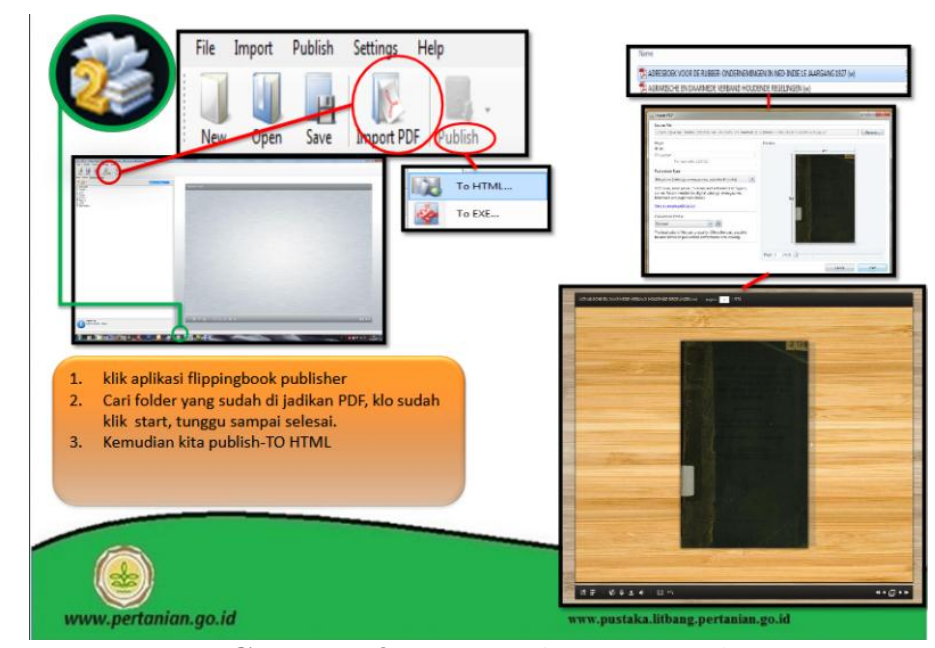

Gambar 9 ProsesFlipping Book

Sumber: Power Point Pusat Perpustakaan dan Penyebaran Teknologi Pertanian

\section{E. KESIMPULAN DAN SARAN}

Proses alih media bahan pustaka atau koleksi tercetak yang dilakukan oleh Pusat Perpustakaan dan Penyebaran Teknologi Pertanian merupakan upaya dari Pelestarian dan Konservasi bahan pustaka atau Preservasi. Hal ini dilakukan untuk menjaga informasi yang terdapat didalam koleksi tersebut agar masih bisa diakses oleh penggun.Hal ini juga merupakan salah satu upaya untuk menjaga ilmu dan informasi yang terdapat dalam koleksi tersebut agar tidak punah.Bedasarkan hasil kegiatan praktek kerja lapangan adalah sebagai berikut.

Pelestarian koleksi yang dilakukan oleh Pusat Perpustakaan dan Pernyebaran Teknologi Pertanian ini terdiri dari tiga tahap, yaitu: tahapan pertama, kegiatan pencegahan yang dilakukan oleh Pusat Perpustakaan dan Penyebaran Teknologi Pertanian adalah dengan beberapa cara sebagai berikut: melakukan pengasapan dengan bahan kimian khusus untuk serangga dan hama pengganggu kertas (fogging), penggunaan alat pengatur kelembaban udara (humidifider), dan penggunakan Silica Gel. Tahapan kedua, penanggulangan, pada kegiatan penanggunalang bahan 
pustaka sudah diidentifikasi mengalami kerusakan, berikut beberapa penanggulangan kerusakan pada bahan pustaka: melakukan pencucian, melakukan penjilidan, dan melakukan laminasi. Tahapan ketiga, proses alih media yang dilakukan dengan cara digitalisasi bahan pustaka. Berikut beberapa tahapan digitalisasi: pemilihan dokumen/bahan pustaka, pengambilan gambar (Scanner/ATIZ), penyuntingan (Editing), Watermarking, PDF dan Flippingbook, Entri Data ke OPAC, dan penyimpanan menggunakan $C D-R O M$

Kegiatan Preservasi khususnya Alih Media bahan pustaka tercetak dalam koleksi Antiquariat yang dilakukan oleh Pusat Perpustakaan dan Penyebaran teknologi Pertanian sudah baik, namun hasil dari alih media tersebut masih sulit diakses oleh pengguna. Pengguna hanya bisa mengakses koleksi tersebut dibagian Antiquariat yang berada di Lantai 9 Pusat Perpustakaan dan Penyebaran Teknologi Pertanian serta mengakses katalog melalui OPAC dari PUSAKA.Bentuk Flippingbook yang sudah tersedia seharusnya dapat diakses menggunakan jaringan LAN perpustakaan agar dapat diakses oleh pengguna di bagian Layanan Sirkulasi ataupun Referensi maupun di gedung perpustakaan layanan digital. Selain itu, seharusnya terdapat ruang multimedia yang dapat memudahkan pengguna untuk mengakses koleksi-koleksi yang berbentuk digital.

\section{DAFTAR PUSTAKA}

Ballofet. Nelly \& Jenny Hille. (2005). Preservation and conservation for libraries and archives. American Library Association.

Basuki, S. (2010). Pengantar Ilmu Perpustakaan. Universitas Terbuka.

Feather, J. (1996). Preservation and the Management of Library Collection. library Association Publishing.

Lasa, H. (2005). Manajemen Perpustakaan. Gama Media.

Lasa, H. (2009). Kamus Kepustakawanan Indonesia. Pustaka Book Publisher.

Margana, S. (2013). Pemanfaatan koleksi langka dalam kegiatan akademis.

Meleong, L. J. (2010). Metodologi Penelitian Kualitatif. Remaja Rosdakarya.

Pendit, P. L. dkk. (2007). Perpustakaan Digital: Perspektif Perpustakaan Perguruan Tinggi Indonesia. CV Sagung Seto.

Rachmawati, T. S. (2018). Media Elekronik di Perpustakaan (E. S. Pawit M. Yusuf (ed.); pp. 26-27).

Shimray, S. R., Ramaiah, C. K. (2017). Issue in preservation of digital cultural heritage. 11th International CALIBER, 146-157.

Sugiyono. (2007). Metode Penelitian Kuantitatif Kualitatif dan $R \& D$. Penerbit Alfabeta. 
